\title{
Solutions for Bullying: Intervention Training for Pre-service Teachers
}

\author{
Lisa Ihnat \\ University of Ottawa \\ J. David Smith \\ University of Ottawa
}

\begin{abstract}
Studies show that teachers lack training and confidence when it comes to intervening effectively in bullying situations. The goal of this study is to respond to the needs of teachers for more formal training on bullying. A two-hour workshop on bullying was developed and offered to pre-service teachers completing a consecutive Teacher Education program in a central-Canadian University. Two parallel questionnaires, each consisting of simulated bullying incidents and standard intervention options, were developed, piloted with a group of experienced teachers, and then used to assess the effect of the workshop on teachers' responses to the bullying. At pre-test, although three-quarters pre-service teachers in the sample had no formal training in bullying intervention strategies, their selected interventions were rated as consistently appropriate (i.e., restorative and relational). Study results revealed that pre-service teachers who participated in the workshop showed improved responses to the bullying scenarios, with the greatest improvements evidenced in their intervention with the children in bullying roles. With the growing legal and moral responsibility that educators have to protect their students from bullying, these findings add to accumulating evidence that training in bullying prevention and intervention should be mandatory for preservice teachers.
\end{abstract}

"When left unchecked, bullies can destroy lives," comments a journalist from the Globe and Mail, in view of the recent suicides of several youth in the United States who had suffered homophobic victimization from their peers (Anderssen, 2010, p. F1). These acts were not isolated incidents nor are they specific to the United States. According to The World Health Organization, Canada ranks $26^{\text {th }}$ out of 35 countries for the proportion of children and youth who bully and $27^{\text {th }}$ in terms of the proportion of children and youth who are victimized (Craig \& Edge, 2008). This is a fact that many consider to be completely unacceptable in a society that prides itself on its tolerant and democratic practices (Anderssen, 2010). As individuals on the front-line of children's social interactions, teachers play a critical role in assisting students to escape abusive bullying relationships (PREVNet, 2011). Teachers are also in a position to protect children from the toxic effects that bullying can have on their mental health (Conners-Burrow, Johnson, Whiteside-Mansell, McKelvey, \& Gargus, 2009; Klomek et al., 2009). Anxiety, depression, and psychosomatic complaints are frequently exhibited by 
children who bully others (Kaltaila-Heino, Rimpela, Rantanen, \& Rimpela, 2000). Relative to all children involved in bullying, children who are both victimized and who bully others run the highest risk of developing symptoms of depression including the highest levels of suicidal ideation (Conners-Burrow et al., 2009; Roland, 2002).

Correctly identifying bullying incidents and being able to respond appropriately are key to reducing bullying, yet teachers, both pre-service and experienced, generally express feeling inadequate to intervene in bullying incidents and report that they lack the knowledge necessary to do so (BlainArcaro, Smith, Cunningham, Vaillancourt, \& Rimas, 2011; Beran, 2006; Mishna, Scarcello, Pepler, \& Wiener, 2005). This is an alarming finding, as teachers are generally less inclined to investigate reports of bullying when they question their capacity to resolve the potential bullying situation at hand (Novick \& Isaacs, 2010). The risk is further compounded by teachers' perceptions that school administrators do not adequately support them, and that they lack resources to address bullying effectively (Mishna et al., 2005). Although additional research is required to determine the best interventions to address bullying, some findings indicate that teachers' attitudes toward bullying can be a formidable barrier to progress (Bauman \& Hurley, 2005). For example, teachers have been reported to perceive children who behave aggressively or bully as "deserving" of the victimization that they themselves experience (Olweus, 2001). Teachers are more likely to intervene in situations that match their personal assumptions about what it means to be a "victim" (Mishna et al., 2005). Finally, when teachers indicate that they are more likely to choose situations in which a victimized child demonstrates observable signs of distress relative to situations in which victimization children hide their reactions to bullying (Blain-Arcaro et al., 2011).

Mishna et al. (2005) emphasized the importance of avoiding stereotypical views of victimized children and of recognizing that certain victim characteristics are not necessarily present in bullying situations. The present study builds on this notion, and we hypothesize that the diversity in children's behavioural responses to victimization (e.g., from accepting the bullying passively to fighting back) may render the task of deciding how to intervene confusing and problematic for teachers. Therefore, one objective of our study is to determine whether or not teachers' decisions about how they intervene in specific situations varies according to victimized children's responses to the bullying the experience.

A teacher education program can be an ideal context in which the difficulties that teachers report in addressing bullying might be addressed. Previous research has shown that formal training on bullying can lead to significant improvements in pre-service teachers' knowledge and attitudes towards bullying by fostering greater self-efficacy (Benítez, García-Berben, \& Fernández-Cabezas, 2009). Therefore, another key objective of this study is to determine, using a controlled pre-post experimental research design, if preservice teachers' responses to bullying scenarios improve following participation in a workshop on bullying intervention.

\section{Method}

\section{Participants}

The participants in this study were recruited from a course entitled Counselling 
Applications in School Contexts, which is offered as an optional within the Teacher Education (BEd) program at a central-Canadian university. The course addresses the roles of teachers in promoting children's development and mental health, and the topic of bullying prevention and intervention connects closely to the course objectives. The Teacher Education program from which participants were recruited is a consecutive program: all candidates must have completed at least an undergraduate degree from a university to gain admission to the program. The program consists of 36 credits of academic courses completed on a full-time basis over an eight-month period along with two mandatory 4-week classroom placements.

Four professors teaching the course in 2011 accepted the opportunity to have the lead researcher (LI) come to their classes to present a workshop on bullying. All students in the classes (representing all panels of the program: primary, junior, intermediate, and senior grade levels) participated in the workshop, and the research component was voluntary. Enrolment in the four classes ranged from a 28 to 39 students. The final sample for the research study consisted of 66 participants (response rate of $49.0 \%$ ), of which 53 were women.

\section{Measures}

Questionnaire Development. In the first phase of this study, two questionnaires were developed: one for pre-test and a parallel version for post-test. The questionnaire that was distributed to participants in the pre-test condition included 6 questions pertaining to the demographic characteristics of the sample. Participants were asked to indicate from several multiple-choice options their gender, age, level of education, previous teaching experience, panel, and previous exposure to formal and informal training on bullying or bullying prevention.

Both pre-test and post-test questionnaires included six written vignettes that described bullying incidents and some of the behavioural characteristics of the children involved. The vignettes included 1-2 sentences describing the bullying incident itself, and 1-2 sentences outlining the behavioural responses of the children being victimized (see Figure 1 for a sample vignette). In each vignette, two children were named and presented as the protagonists in the scenario: a child who initiated an act of bullying and a child who was victimized. Gender of the children was systematically varied across the vignettes: two involved a male bullies and victims, two involved female bullies and victims, and two involved cross-gender bullying. The behavioural responses of the victimized child were varied across the six scenarios, such that two of the vignettes portrayed one of three possible behaviours: a passive reaction (passive victim), an aggressive reaction (aggressive victim), and subsequent bullying (bully-victim).

The descriptions of the incidents in each vignette illustrated a power difference between the victim and the bully, in order to adhere to the definition of bullying that has been widely accepted by researchers in the field. While the repetition of the negative act over time is also a typical component of the definition of bullying, it was not included in the vignettes so as to make the scenarios as externally valid as possible. Teachers often only have access to immediate and observable behaviours at any given time. The incidents that were illustrated all constituted commonplace, non-physical acts of bullying and were appropriate to the ages of the children involved in the scenarios. Teachers' 
views of direct and physical forms of bullying are such that they are more likely to believe that these acts merit intervention (Mishna et al., 2005). The subtler incidents portrayed in these vignettes were expected to elicit a wide range of responses from participants. The vignettes depicted incidents of spreading rumours or gossiping, name-calling or humiliation, and indirect intimidation (e.g., stealing or damaging a child's property). Each vignette on the post-test was developed in parallel with a vignette from the pre-test. Parallel vignettes are identical in length and matched on the characteristics of the individuals involved as well as the type of bullying perpetrated and the response of victimized children. Only the specific behaviours of the children involved were varied. The goal was to control for any practice effects that might occur due to participants having the opportunity to complete the same questionnaire twice.

As forms of bullying vary from elementary school to high school (Vaillancourt et al., 2008), the present study was limited to an exploration of teacher responses to bullying incidents occurring among children in grades 4-8, which typically correspond to the highest rates of bullying in childhood (Pepler, Craig, Yuile, \& Connolly, 2004). In addition, the names of the children included those that might be commonly attributed to a variety of ethnicities in order to portray the Canadian public school student body as accurately as possible. To counter any possible effects of the order presentation as well as the names given to children on participants' response, the order of the vignettes within the questionnaires was reversed in half of the questionnaires, as were the names of the children depicted in the scenarios. This yielded four different versions of both the pre-test and post-test questionnaires.

Following the development of the vignettes, a set of response options was developed that was presented after each vignette on both the pre-test and posttest (see Figure 1 for a sample item including the list of response options). The response options were identical across vignettes and across conditions. Two objectives were envisaged in this phase of the questionnaire development: the response options were to be realistic (in terms of what teachers might be able to do when they witness an incident of bullying) and they needed to be exhaustive (capturing a full range of teacher responses). In order to fulfill the latter criterion, response options were generated on the basis of McCold and Wachtel's (2003) Social Discipline Window, which is separated into restorative, permissive, punitive, and neglectful quadrants, as well as from Smith's (2008) suggestions for restorative interventions in the classroom. As illustrated in Figure 1 , the first 13 response options were displayed twice: in a column labelled with the victimized child's name and in a second column labelled with the bullying child's name. The last two response options were listed only once per vignette as they involved (a) the victim-bully dyad and (b) the entire classroom. Participants selected as many response options as they deemed appropriate.

The pre-test questionnaire was evaluated in a pilot study. A group of six experienced teachers from two public elementary schools in Ontario were recruited on a voluntary basis to participate in the pilot study. Participants were asked to provide written feedback on the pertinence and clarity of the vignettes and response options, the ease of completing the questionnaire, and any additional aspects that they felt could be improved. This resulted in a variety of minor changes being made to the questionnaires.

Once the questionnaires were finalized, a panel of experts (including two professors and a post-doctoral fellow from the Faculty of Education, all with expertise in bullying prevention) devised a scoring key by assigning a valence 
for each response option presented within each of the scenarios. A value of +1 was given to options deemed appropriate within a given scenario, a value of 0 was attributed to options considered neutral (neither particularly helpful nor detrimental), and a value of -1 was given to options deemed inappropriate. Victim and bully responses were scored separately, and along with the additional two response options (dyad and classroom) yielded 28 different valences per item. While the valences of most response options remained constant across the vignettes, some did vary as a function of the particular characteristics of the scenarios.

Item scores were calculated by summing the values of all selected response options and then dividing by the number of responses selected. This later step prevented the inflation of scores simply by selecting more responses. Item scores were summed to generate a total scale score. For the purposes of this study, three separate total scores were calculated: a score for responses to the victimized child (13 options), a score for responses to the bullying child (13 options), and a full-scale score (28 options). Positive scores indicated an overall tendency to respond appropriately within the bullying scenarios.

Workshop. The workshop offered in the context of this study was developed on the basis of material provided to the researchers by PREVNet (2011). PREVNet (Promoting Relationships and Eliminating Violence Network; see prevent.ca) is federally funded (Networks of Centres of Excellence) Canadian organization comprising researchers and non-governmental organizations (e.g., Scouts Canada, The Canadian Teachers Federation) devoted to the mission of bullying prevention and positive youth development. The workshop was designed to sensitize pre-service teachers to the different roles that children adopt in bullying incidents, the types of problematic behaviours that victimized children may exhibit, the psychological repercussions of bullying on all of the children involved. The workshop covered relationship-based solutions to bullying in line with PREVNet's recommendations (2011). The workshop was highly interactive. Students were asked to reflect on the different bullying incidents they might encounter in a school environment, and whole-class discussions were facilitated about interventions that would be appropriate in dealing with these situations based on material in the presentation. Particular emphasis was placed on devising interventions that are restorative in nature. Such strategies involved for example, leading a problem-solving conversation with the children involved in a bullying incident in an attempt to understand the children's views of what occurred, encouraging the children to explore their feelings associated with the event and to speculate about the impact of their behaviour on others, and collaborating with them to establish appropriate consequences that would allow the wrongdoer (s) to make amends (Smith, 2008).

\section{Procedure}

The researchers solicited the collaboration of four different professors teaching the Counselling Applications course in the Teacher Education Program. Classes were randomly assigned to the experimental and control conditions. One week prior to the workshop, the first author visited the classes to introduce the research project and solicit the participation of the students. At the end of the introductory presentation, the researcher distributed packages containing the 
consent form and pre-test questionnaire to all students in the classroom, and then left the classroom. Students who decided to participate submitted completed documents anonymously to the researcher via internal mail at the University.

One week following the distribution of pre-test questionnaires in each class, the bullying workshop was presented in each of the four classes. In the two experimental classes, participants were asked to complete the post-test questionnaire immediately following the workshop and to return it immediately to the student researcher. Participants in the control group completed the posttest questionnaires in class immediately before the beginning of the workshop. Only questionnaires that had matching pre-test questionnaires were retained for this study.

\section{Results}

\section{Sample characteristics}

Demographic information collected on all participants at pre-test is summarized in Table 1. It reveals that while the vast majority of pre-service teachers have acquired some knowledge of the nature of bullying and bullying prevention $(90.9 \%)$, only half of them have done so through formal means $(53.0 \%)$, and less than one fifth $(19.0 \%)$ of participants with formal training have received training in bullying prevention. In order to test for differences between the control and experimental groups on gender, previous teaching experience, and reported exposure to knowledge on bullying, all bi-variate combinations were analyzed with four chi-squared tests. The results reveal that both the control and experimental groups did not differ significantly with respect to these characteristics.

\begin{tabular}{|l|l|l|l|l|}
\hline & Female & $\begin{array}{l}\text { Teaching } \\
\text { Experience }\end{array}$ & Formal Training & Informal Training \\
\hline $\begin{array}{l}\text { Treatment } \\
(\mathrm{N}=27)\end{array}$ & $81.5 \%$ & $85.2 \%$ & $62.9 \%$ & $88.9 \%$ \\
\hline $\begin{array}{l}\text { Control } \\
(\mathrm{N}=39)\end{array}$ & $79.5 \%$ & $87.2 \%$ & $46.1 \%$ & $92.3 \%$ \\
\hline
\end{tabular}

Table 1: Participant characteristics

\section{Intervention tendencies}

Pre-service teachers' mean scores were examined on the pre-test vignettes as a means of assessing their approach to dealing with bullying prior to exposure to the workshop. The combined mean for both groups on the total score is 4.24 $(\mathrm{SD}=1.31)$, indicating that participants tended on the whole to select appropriate rather than inappropriate intervention solutions in response to the vignettes. The results also reveal that pre-service teachers' responses to victimized children and children who bully are generally similar. The combined group means are $4.19(\mathrm{SD}=1.25)$ for victim scores and $4.21(\mathrm{SD}=1.39)$ for bully scores.

An examination of pre-test data also reveals that participants' mean total 
scores, victim scores, and bully scores on the pre-test were appropriate overall, regardless of the way in which victimized children responded to their experiences of bullying. As displayed in Table 2, means across all 3 types of victim reactions to the bullying have a positive valence. A one-way repeated measures ANOVA was carried out on the total scores, with type of victim behaviour (e.g., aggressive, passive, bully-victim) entered as the within-subjects factor. The alpha level was set at .05 for this test as well as for all subsequent analyses. The results revealed a statistically difference in intervention scores as a function of the way in which victimized children reacted to the bullying, $\mathrm{F}(2$, $126)=3.65, p=.03$. In order to explore the source of the difference observed, three subsequent one-way repeated measures ANOVAs were conducted, first on victim scores only, second on bully scores, and third on the two classroom items. In all analyses, type of victim behaviour was entered as within-subjects factor. None of the test results reached statistical significance, $F(2,122)=1.29, \mathrm{p}$ $=.28$ for victim scores; $\mathrm{F}(2,122)=1.89, \mathrm{p}=.16$ for bully scores, and $\mathrm{F}(1,33)=$ $0.85, \mathrm{p}=.39$ for classroom scores. These results suggest that the differences observed exist with respect to the totality of the bullying interventions proposed by participants rather than their targeted responses to the bully, to the victim, or in the classroom.

\begin{tabular}{|l|l|l|l|}
\hline & Aggressive Victim & Passive Victim & Bully-victim \\
\hline Total Scores & $1.44(0.47)$ & $1.33(0.47)$ & $1.44(0.47)$ \\
\hline Victim Scores & $1.43(0.52)$ & $1.30(0.69)$ & $1.43(0.51)$ \\
\hline Bully Scores & $1.45(0.53)$ & $1.35(0.54)$ & $1.36(0.52)$ \\
\hline
\end{tabular}

Table 2: Means (SD) for pre-test scores by type of victim behaviour $(\mathrm{N}=64)$

\section{Impact of the Workshop}

The impact of the workshop on pre-services teachers' responses to the bullying scenarios was evaluated through an initial $2 \times 2$ repeated measures ANOVA. (See Table 3 for descriptive statistics by group and by time.) The first factor, Time, consisted of two levels (pre-test, post-test) and was entered as the within-subjects factor. Group also included two levels (control, experimental) and was entered as the between-subjects factor. The result of this test indicated that the effect of the workshop was just short of statistical significance, $\mathrm{F}(1,61)=3.34, \mathrm{p}=.07$. Given this marginally significant result, and the exploratory orientation of this study, we decided to proceed with additional follow-up analyses.

\begin{tabular}{|l|l|l|l|}
\hline Condition & Score & Control Group & Experimental Group \\
\hline \multirow{3}{*}{ Pre-test } & Total & $4.18(1.31)$ & $4.34(1.31)$ \\
\cline { 2 - 4 } & Victim & $4.10(1.24)$ & $4.32(1.27)$ \\
\cline { 2 - 4 } & Bully & $4.16(1.39)$ & $4.28(1.31)$ \\
\hline \multirow{3}{*}{ Post-test } & Total & $4.00(1.38)$ & $4.60(1.21)$ \\
\cline { 2 - 4 } & Victim & $3.98(1.49)$ & $4.48(1.32)$ \\
\cline { 2 - 4 } & Bully & $3.92(1.45)$ & $4.55(1.48)$ \\
\hline
\end{tabular}

Table 3: Mean (SD) scores by group and by condition 
Two subsequent $2 \times 2$ repeated measures ANOVAs were used to test differences in participants' specific responses to the victims and the bullies depicted in the scenarios from pre-test to post-test. The interaction of Time and Group for victim responses did not reach statistical significance, $F(1,59)=0.81$, $\mathrm{p}=.37$. While the interaction of Time and Group for bully responses also proved non-significant, the results of the analysis, $\mathrm{F}(1,59)=2.924, \mathrm{p}=.09$, again approached statistical significance. These results suggest that the effect of the workshop was primarily demonstrated in the manner that participants proposed to deal with the bullying child in the scenario, rather than the victimized child. The means displayed in Table 3 indicate that responses changed in the direction of becoming slightly more appropriate for experimental group, as was expected, and slightly less appropriate for the control group.

\section{Discussion}

Educators face many significant challenges today to meet the heightened social expectations and legal responsibilities to respond to bullying in their schools. Not the least of these challenges, as confirmed by recent research, is teachers' level of preparedness to deal effectively with bullying that occurs in their midst (Blain-Arcaro et al., 2011; Beran, 2006; Mishna et al., 2005). The current study examined teachers' capacity to effectively respond to bullying incidents in the context of commonplace hypothetical scenarios, the likes of which occur in many schools every day. The design of the study permitted us (a) to assess the effectiveness of teachers' responses nearing the end-point in their coursework in a pre-service education program and prior to the workshop and (b) the impact of a bullying workshop on their intervention decisions. A secondary objective involved exploring whether pre-service teachers' interventions vary as a function of victimized children's behavioural responses (i.e., passive, aggressive, bullying) to the bullying they experienced. Two parallel, externally valid questionnaires depicting hypothetical bullying situations were developed and piloted, permitting repeated assessments of their responses while circumventing practice effects.

\section{Teacher training about bullying}

The results of the present study reveal that while the majority of pre-service teachers have received some sort of formal training on general aspects of bullying, less than one quarter of these students have received formal training on actual bullying prevention and intervention strategies. The data for this study were collected in the last two weeks of students' coursework in a consecutive Teacher Education program. Therefore, our results suggest that the large majority of Teacher Education students may start their careers with no formal training related specifically to bullying prevention and intervention. This finding echoes other observations reported in the literature showing that many teachers have not received formal training in bullying prevention (Beran, 2006; Blain-Arcaro et al., 2011). As this lack of training may be associated with a lack of confidence reported by teachers in dealing with bullying situations (Beran, 2006) and consequently a hesitance to intervene in bullying situations (Novick \& Isaacs, 2010), the results of this study point to a pressing need for more extensive formal training on bullying prevention and intervention for pre-service teachers. 


\section{Intervention tendencies}

In spite of most pre-service teachers lacking formal training in bullying intervention prior to participating in the workshop, participants generally opted for appropriate interventions over inappropriate ones in their responses to the bullying scenarios. Responses deemed to be appropriate by a panel of bullying experts were primarily aligned with the restorative quadrant of McCold and Wachtel's (2003) Social Discipline Window. These results suggest that pre-service teachers generally value the use of relationship-based and formative approaches to dealing with bullying situations over less effective intervention strategies, such letting the children deal with it themselves (neglectful) or suspending them from recreation time (punitive).

This is a positive finding that may have important implications for what the literature currently suggests about teachers' views of intervention strategies. The results of this study counter previous findings suggesting that teachers generally hold attitudes about bullying that researchers deem unfavourable and likely to produce ineffective responses to bullying incidents (Bauman \& Hurley, 2005). The link between attitudes and behaviour, however, may be tenuous, at least in a bullying context. Certain authors have concluded that the link between children's attitudes towards bullying and actual bullying behaviour is only moderate (Boulton et al., 1999; Salmivalli \& Voeten, 2004). While most children may report that they have anti-bullying attitudes, many still engage in bullying behaviours. In the same vein, unfavourable attitudes towards bullying among school personnel may not necessarily lead to inappropriate interventions. Attitude surveys fail to account for powerful situational influences on decision making (Ross \& Nisbett, 1991), which may also be operative to some degree in hypothetical bullying scenarios that have high external validity.

A second finding revealed by the results of this study is that there is little difference in the level of appropriateness of pre-service teachers' responses to children who are victimized compared to those who bully prior to participating in the bullying workshop. Both were equally appropriate in orientation. This finding is equally positive, suggesting that children who bully are not generally met with a higher degree of punishment than children who are victimized. Previous authors have observed that teacher trainees experience insecurities as to how to deal with children who bully in particular (Nicolaides, Toda, \& Smith, 2002). The results of this study suggest that, while they may be lacking in confidence, pre-service teachers' select intervention strategies that are likely to be effective.

On the other hand, some research suggests that teachers may believe that children who are bullied and who bully others deserve the victimization they experience (Olweus, 2001). This finding finds some empirical support in children's reports that indicate that children who are "bully-victims" report higher levels of maltreatment by staff in schools than passive victims and even children who only bully (Khoury-Kassabri, 2009). However, the results of this study reveal that pre-service teachers' responses to bullying situations involving victimized children who respond aggressively or who bully tend to be more appropriate than their responses to situations involving children who react passively to bullying. This finding suggests that pre-service teachers may have some reluctance about using relationship-based solutions to bullying that involves children who respond passively to being victimized. Anecdotally, educators have sometimes expressed reticence to us about using restorative 
approaches in situations of bullying, fearing re-victimization of children, particularly for passive children who have considerable difficulty defending themselves. These results lead us to speculate that pre-service teachers in this study may interpret the reactions of passive victims in the scenarios as evidence of a diminished capacity to face the children who bullied them in the context of restorative approaches to bullying. Consequently, it is possible that teachers "crack down" on the bullies of children who respond passively, accounting for responses that are less restorative in approach. Conversely, teachers may use more appropriate interventions in bullying situations involving victimized children who respond aggressively or by bullying, anticipating the negative effect that their aggressive reactions may have on other children. Finally, it has been observed that the level of distress displayed by children who are victimized is predictive of teachers' decisions to intervene in bullying situations (Blain-Arcaro et al., 2011). It is possible that the distress displayed by children who respond to victimization passively is not sufficiently evident to elicit action from the adults in their school environment. This may lead to neglectful responses on the part of their teachers. These speculations, however, require empirical scrutiny in future research.

\section{Impact of the workshop}

A key objective of the present study was to determine the degree to which a workshop on bullying intervention could improve pre-service teachers' responses to the hypothetical bullying situations. The results suggest that the workshop may have indeed led to changes in pre-service teachers' knowledge of how to respond appropriately to bullying situations. Although marginal in terms of statistical significance, the results of this study suggest that pre-service teachers' intervention responses may become more appropriate as a result of additional training. This finding is aligned with what other authors have suggested and observed about the integration of bullying training into the curriculum of Teacher Education programs. Beran (2005) recommended the implementation of bullying intervention training in order to combat insecurities that pre-service teachers report when confronted with incidents of bullying. Benítez, García, and Fernández (2009) found that pre-service teachers greatly benefited from a course on bullying. The findings of the present study support the idea that bullying training may be advantageous to pre-service teachers and may represent a potential pathway to solutions for bullying.

In an effort to understand the sources of the changes produced by the workshop, pre-service teachers' responses to the victimized children and the children who bullied were analyzed separately. The results indicate that there was no change in participants' responses to the victimized children a result of the workshop. Changes in responses to the children who bullied were marginally significant, and in the predicted direction of being more appropriate following the workshop. These results lead us to tentatively conclude that pre-service teachers seem to show increased sensitivity towards the needs of children who bully when they have received a formal training opportunity in bullying prevention and intervention.

\section{Limitations}

Several limitations of this study deserve mention here. One significant limitation 
concerns the involvement of pre-service teachers all training in the same program. It is impossible to determine the degree to which these students are representative of BEd students in other consecutive Teacher Education programs. In addition, participants were few in number and were recruited in an optional program course. It is possible, for example, that these students already have heightened sensitivity to bullying concerns and stronger foundational knowledge of learning and child development that could impact their questionnaire responses. These issues raise questions about the representativeness of the study sample, and consequently limit significantly the generalizability of our findings. Only future research with samples drawn from other institutions and courses can provide additional insight on these issues.

Another limitation concerns the two-hour workshop offered as the intervention in this study. A workshop of such limited scope and length allows for only limited coverage of a broad and complex topic. It would be interesting to determine if a longer workshop, carried out in several instalments over a longer period of time, would lead to even greater learning and stronger effects in the experimental condition. The study is also limited by the lack of a time lapse between the workshop and the post-test. Consequently, it is impossible to determine to what degree responses on the post-test were influenced by any transient demand characteristics of the workshop versus real learning that would positively impact participants' educational practices. A future replication of this study that includes a third data collection point at least several weeks after the workshop would provide some needed clarification on this issue.

Finally, the present study involved an investigation of pre-service teachers' hypothetical responses to bullying situations, rather than the exploration of the actual responses teachers display when faced with real-life bullying incidents at school. While the bullying scenarios presented to the participants were developed to maximize external validity, it is not possible to determine the degree to which the findings of the present study are applicable to actual practice. Certainly, no hypothetical decision making task can fully replicate the conditions of responding in situ to bullying incidents when the well-being of children is at stake.

\section{Conclusion}

The present study builds on existing knowledge of teacher interventions in bullying situations. Our findings indicate that pre-service teachers are on the right path to devising interventions in bullying incidents that on the whole are appropriate, formative, and restorative in nature, taking into consideration the relational dimensions that underpin bullying (PREVNet, 2011). The present study highlights a need for pre-service teachers to be alert to experiences of victimization involving children who do not display aggression or other disruptive and problematic behaviours in response to their bullying experiences. Given other recent research indicating that teachers are more likely to intervene when victimized children manifest obvious signs of distress (Blain-Arcaro et al., in press), it is critical that all adults who work with children understand that how a child responds to bullying is not a reliable sign of the harm it causes. Our results suggest that a workshop on bullying offered within the context of a Teacher Education program may prove advantageous to pre-service teachers, particularly with respect to how they report dealing with children who bully. With increasing demands and responsibilities on teachers and school authorities 
to address bullying along with evidence that pre-service teachers can learn to respond more effectively to bullying, we suggest that the time has come to make training in bullying prevention and intervention a mandatory part of the curriculum in teacher education programs.

\section{Acknowledgements}

This article is based on the MA thesis completed by the first author. Portions of this article were present at the 2011 conference of the Canadian Psychological Association, Toronto.

\section{References}

Anderssen, E. (2010, October 30). Why we're losing the fight against bullying. The Globe and Mail, pp. F1, F4.

Bauman, S., \& Hurley, C. (2005). Teachers' attitudes and beliefs about bullying: Two exploratory studies. Journal of School Violence, 4, 49-61.

Benítez, J. L., García-Berben, A., \& Fernández-Cabezas, M. (2009). The impact of a course on bullying within the pre-service teacher training curriculum. Electronic Journal of Research in Educational Psychology, 7(1), 191-208. Retrieved from http:// ovidsp.tx.ovid.com.proxy.bib.uottawa.ca/sp-3.4.2a/ovidweb.cgi

Beran, T. N. (2006). Preparing teachers to manage school bullying: The hidden curriculum. Journal of Educational Thought, 40(2), 119-128. Retrieved from http:// vnweb.hwwilsonwen.com.proxy.bib.uottawa.ca/jump

Blain-Arcaro, C., Smith, J. D., Cunningham, C., Vaillancourt, T., \& Rimas, H. (2012). Contextual attributes of indirect bullying situations that influence teachers' decisions to intervene. Journal of School Violence, 11, 226-245.

Boulton, M. J., Bucci, E., \& Hawker, D. S. D. (1999). Swedish and English secondary school pupils' attitudes towards, and conceptions of, bullying: Concurrent links with bully/ victim involvement. Scandinavian Journal of Psychology, 40, 277-284.

Conners-Burrow, N. A., Johnson, D. L., Whiteside-Mansell, L., McKelvey, L., \& Gargus, R. A. (2009). Adults matter: Protecting children from the negative impacts of bullying. Psychology in the Schools, 46, 593-603.

Craig, W. M., \& Edge, H. M. (2008, March 10). Healthy settings for young people in Canada: Bullying and fighting. Retrieved from http://www.phac-aspc.gc.ca/dca-dea/yjc/ ch5_105_108-eng.php\#h

Kaltaila-Heino, R., Rimpela, M., Rantanen, P., \& Rimpela, A. (2000). Bullying at school -an indicator of adolescents at risk for mental disorders. Journal of Adolescence, 23, 661-674.

Khoury-Kassabri, M. (2009). The relationship between staff maltreatment of students and bully-victim group membership. Child Abuse and Neglect, 33, 914-923.

Klomek, A. B., Sourander, A., Niemela, S., Kumpulainen, K., Piha, J., Tamminen, T., \& Gould, M. S. (2009). Childhood bullying behaviors as a risk for suicide attempts and completed suicides: A population-based birth cohort study. Journal of American Academy of Child and Adolescent Psychiatry, 48(3), 254-261.

McCold, P. \& Wachtel, T. (2003). In pursuit of paradigm: A theory of Restorative Justice. Retrieved from http://www.realjustice.org/articles.html?articleId=424

Mishna, F., Scarcello, I., Pepler, D., \& Wiener, J. (2005). Teachers' understanding of bullying. Canadian Journal of Education 28, 718-738. 
Nicolaides, S., Toda, Y., \& Smith, P. K. (2002). Knowledge and attitudes about school bullying in trainee teachers. British Journal of Educational Psychology, 72, 105-118.

Novick, R.M., \& Isaacs, J. (2010). Telling is compelling: The impact of student reports of bullying on teacher intervention. Educational Psychology, 30(3), 283-296. doi: $10.1080 / 01443410903573123$

Olweus, D. (2001). Peer harassment: A critical analysis of some important issues. In J. Juuvonen \& S. Graham (Eds.), Peer harassment in school: The plight of the vulnerable and victimized (pp. 3-20). New York: Guilford Press.

Pepler, D., Craig, W. M., Yuile, A., \& Connolly, J. (2004). Girls who bully: A developmental and relational perspective. In M. Putallaz \& J. Kupersmidt (Eds.), Aggression, antisocial behavior, and violence among girls (pp. 90-109). New York: Guilford Publications.

PREVNet (2011). Promoting relationships and eliminating violence network/Home. Retrieved from: prevnet.ca.

Roland, E. (2002). Bullying, depressive symptoms and suicidal thoughts. Educational Research, 44(1), 55-67. doi:10.1080/00131880110107351

Ross, L., \& Nisbett, R. E. (1991). The person and the situation: Perspectives of social psychology. New York: McGraw-Hill

Salmivalli, C. \&Voeten, M. (2004). Connections between attitudes, group norms, and behaviour in bullying situations. International Journal of Behavioural Development, 28(3), 246-258. Doi:10.1080/01650250344000488

Smith, J. D. (2008). Promoting a positive school climate: Restorative practices for the classroom. In D. Pepler \& W. Craig (Eds.), Understanding and addressing bullying: An international perspective (pp. 132-141). Bloomington, IN: AuthorHouse.

Vaillancourt, T., McDougall, P., Hymel, S., Krygsman, A., Miller, J., Stiver, K., \& Davis, C. (2008). Bullying: Are researchers and children/youth talking about the same thing? International Journal of Behavioral Development, 32(6), 486-495.

Lisa Ihnat, MA, completed her master's degree in Educational Counselling at the University of Ottawa. She works as a counsellor at the Centre francophone de Toronto.

David Smith, PhD, is a counselling professor at the Faculty of Education, University of Ottawa. He is a founding member of PREVNet (www.prevnet.ca), a Canadian network of researchers and service organizations dedicated to eliminating violence and bullying. Please send inquiries about this article to David.Smith@uottawa.ca. 